\title{
Omalizumab treatment of moderate to severe asthma in the adolescent and pediatric population
}

\author{
John O'Quinn ${ }^{1 *}$, Stephanie Santucci', Diana Pham¹, Zave Chad², lan MacLusky², Joseph Reisman², William Yang ${ }^{1,3}$ \\ From Canadian Society of Allergy and Clinical Immunology Annual Scientific Meeting 2014 \\ Ottawa, ON, Canada. 23-26 October 2014
}

\section{Background}

In Canada and the US, omalizumab is indicated for adults and adolescents ( $>12$ years of age) with moderate to severe persistent allergic asthma. In the EU, omalizumab has been approved for children (age $6-11$ years) since 2009. The pediatric population within Canada and the United States has very few treatment options available for severe asthma. Current treatments options can lead to other health concerns such as adrenal insufficiency and osteoporosis. These cases demonstrate that early treatment of moderate to severe asthma with omalizumab is an effective treatment and can help to prevent or reverse damage done by long-term use of other treatment options.

\section{Methods}

A retrospective chart review of our database was performed and patients $\leq 17$ years of age receiving omalizumab treatment were evaluated. Data was collected on $\mathrm{FEV}_{1}$, inhaled corticosteroid (ICS) and oral corticosteroid (OCS) use.

\section{Results}

12 patients were identified as 17 years old or younger at the start of treatment with omalizumab. After the first 6 months of treatment, all 12 patients showed an increase in FEV1 results and a decrease in ICS dose. Results also indicated a decrease in OCS use for those patients taking daily dose as well as those who required periodic bursts to control asthma exacerbations.

\section{Conclusion}

Early treatment of moderate to severe asthma with omalizumab in adolescent/pediatric patients may improve quality of life and help prevent health concerns associated with

${ }^{1}$ llergy and Asthma Research Centre, Ottawa, ON, Canada

Full list of author information is available at the end of the article side effects and/or long term use of ICS and OCS in growing children. Juvenile osteoporosis can be a significant problem because it occurs during the prime bone-building years and may lead to reduced peak bone mass and increased risk for osteoporosis later in life. Regular reevaluation of the treatment regime to ensure the use of the lowest effective dose of corticosteroids and consideration of other treatments would also be beneficial.

\section{Authors' details}

${ }^{1}$ llergy and Asthma Research Centre, Ottawa, ON, Canada. ${ }^{2}$ Department of Pediatrics, University of Ottawa, ON, Canada. ${ }^{3}$ University of Ottawa Medical School, Ottawa, ON, Canada.

Published: 18 December 2014

doi:10.1186/1710-1492-10-S2-A34

Cite this article as: O'Quinn et al:: Omalizumab treatment of moderate to severe asthma in the adolescent and pediatric population. Allergy, Asthma and Clinical Immunology 2014 10(Suppl 2):A34.

\section{Submit your next manuscript to BioMed Central and take full advantage of: \\ - Convenient online submission \\ - Thorough peer review \\ - No space constraints or color figure charges \\ - Immediate publication on acceptance \\ - Inclusion in PubMed, CAS, Scopus and Google Scholar \\ - Research which is freely available for redistribution \\ Submit your manuscript at www.biomedcentral.com/submit}

